\title{
Persistence of Phenylamide Insensitivity in Pseudoperonospora humuli
}

\author{
David H. Gent, United States Department of Agriculture-Agricultural Research Service, Forage Seed and Cereal \\ Research Unit, and Oregon State University, Department of Botany and Plant Pathology, Corvallis 97331; and Mark \\ E. Nelson and Gary G. Grove, Department of Plant Pathology, Washington State University, Irrigated Agriculture \\ Research and Extension Center, Prosser 99350
}

\begin{abstract}
Gent, D. H., Nelson, M. E., and Grove, G. G. 2008. Persistence of phenylamide insensitivity in Pseudoperonospora humuli. Plant Dis. 92:463-468.

Downy mildew, caused by Pseudoperonospora humuli, is an important disease of hop in most production regions in the northern hemisphere. Insensitivity to phenylamide fungicides was detected in isolates of $P$. humuli in production regions in Oregon and Idaho in 1992, and these fungicides since have been used on a limited basis. In this study, the prevalence of phenylamide insensitivity among isolates of $P$. humuli collected from 2005 to 2007 in the northwestern United States was quantified using a leaf disk assay with a discriminating dose $(25 \mu \mathrm{g} / \mathrm{ml})$ of either metalaxyl or mefenoxam with inoculum derived from 201 systemically infected diseased shoots (basal spikes) collected from 6, 10, and 11 hop yards in Idaho, Washington, and Oregon, respectively. A subset of 47 basal spike isolates and 42 monosporic isolates collected from two yards in Idaho and nine yards in Oregon during 2006 and 2007 were assayed using a dilution series of metalaxyl to determine the effective dose that inhibited $50 \%$ of the incidence of sporulation $\left(\mathrm{ED}_{50}\right)$. Insensitivity to mefenoxam was detected in 31 of $74(41.9 \%)$ basal spikes collected from 13 hop yards. Insensitivity to the related compound metalaxyl was detected in 52 of $80(65 \%)$ spikes collected from nine hop yards, including four hop yards in Washington. Log $\mathrm{ED}_{50}$ values ranged from -2.25 to 2.67 for basal spike isolates and -2.27 to 2.98 for monosporic isolates and had a similar distribution. $\log \mathrm{ED}_{50}$ values for monosporic isolates and entire basal spike isolates were significantly associated. However, the slope of the regression line was less than 1, indicating that the $\log \mathrm{ED}_{50}$ values obtained from entire basal spike isolates were greater than the corresponding $\log \mathrm{ED}_{50}$ values obtained from a monosporic isolate obtained from that spike. This research suggests that insensitivity to phenylamide fungicides is a stable phenotype in $P$. humuli. Management of downy mildew should rely on measures other than these fungicides in yards or regions where phenylamide insensitivity is prevalent, which is now known to include certain hop yards in Idaho, Oregon, and Washington.
\end{abstract}

Additional keywords: disease management, Humulus lupulus, Ridomil

Hop (Humulus lupulus) is a dioecious climbing perennial bine grown for its female flowers (cones). The commercial value of hop cones is the result of lupulin glands in the cones that produce soft resins ( $\alpha$ and $\beta$ acids) and essential oils that impart flavor and aroma to beer and aid in preservation because of their antimicrobial properties (3). In the United States, nearly

Corresponding author: D. H. Gent

E-mail: gentd@ onid.orst.edu

The use of trade, firm, or corporation names in this publication is for the information and convenience of the reader. Such use does not constitute an official endorsement or approval by the United States Department of Agriculture or the Agricultural Research Service of any product or service to the exclusion of others that may be suitable.

Accepted for publication 7 November 2007.

\section{doi:10.1094/PDIS-92-3-0463}

This article is in the public domain and not copyrightable. It may be freely reprinted with customary crediting of the source. The American Phytopathological Society, 2008. all commercial hop production occurs in the Pacific Northwest states of Idaho, Oregon, and Washington.

Downy mildew, caused by the oomycete pathogen Pseudoperonospora humuli, is an important disease in most regions of hop production in the northern hemisphere (38). The disease is favored by extended periods of wetness, high humidity, and temperatures ranging from 12 to $23^{\circ} \mathrm{C}$ (23-25,37,38). During such conditions, the pathogen may infect leaves and shoots, and cause systemic infections of crowns and roots. Perennation of $P$. humuli occurs as mycelia in infected crowns and roots, and the pathogen grows systemically into developing buds during the fall $(8,40)$. The following season, the disease appears first on newly emerged and infected shoots ("basal spikes"; 22,38). Basal spikes are stunted and have brittle, downward-curled leaves from which masses of purple to black sporangiophores and sporangia are produced, which serve as primary inocula to infect other leaves and shoots, resulting in "secondary basal spikes". Reductions in cone yield result from infection of the main bines or the cone-bearing lateral branches, which arrests development of these shoots. Later infections of developing cones may cause complete loss of marketable yield through cone abortion, reductions in $\alpha$ acid, and quality losses (38). In certain cultivars, the disease may cause a crown rot and subsequent plant death $(23,33,38,40)$.

Management of downy mildew relies largely on regular application of fungicides $(8,21,23,41)$ and cultural practices such as crown pruning and rouging of diseased plants $(7,36,38,41)$. Hunger and Horner (21) reported that, in 1981, metalaxyl was applied to all commercial hop yards in Oregon planted to susceptible cultivars and provided nearly complete control of downy mildew. Anecdotal reports of control failures attributed to metalaxyl insensitivity were reported within a few years of commercial use of this fungicide, and metalaxyl insensitivity later was confirmed experimentally in hop yards in Oregon, Idaho, and Germany $(19,28)$. Formal resistance management programs were not developed or implemented. Therefore, hop growers in these regions have since reduced or ceased use of this fungicide and have relied upon other fungicides to manage downy mildew (32).

Metalaxyl and its closely related entantiomer, mefenoxam, are highly active systemic fungicides in the class phenylamide which specifically inhibit RNA polymerase. Metalaxyl insensitivity is prevalent among oomycete pathogens worldwide $(2,4-6,9,10,15,29,34,35,39,42)$, and rapid shifts from metalaxyl sensitivity to insensitivity have been reported $(10,13$, 17,31). Fewer studies have documented long-term changes in metalaxyl sensitivity after applications of phenylamide fungicides have ceased. In many pathosystems, phenylamide-insensitive isolates have fitness traits similar to $(11,20)$ or superior to that of wild-type isolates $(6,27)$, which may influence the persistence and dissemination of insensitive isolates within a population. Conversely, in Ireland, Dowley and O'Sullivan $(12,14)$ reported that a "small number" (i.e., less than $15 \%$ ) of potato crops were treated with metalaxyl from 1981 to 1984 , and the proportion of metalaxyl-insensitive isolates of Phytophthora infestans decreased from 75 to $6 \%$ within this time. Effective control of potato late blight was achieved when 
metalaxyl was used in a mixture with mancozeb 4 years after the initial reports of insensitivity (13).

The dynamics and persistence of metalaxyl insensitivity in Pseudoperonospora humuli have not been reported. Based on the dynamics of phenylamide insensitivity in other pathosystems $(11,12,14)$, acceptable control of hop downy mildew may be possible with limited use of phenylamide fungicides because of attrition of insensitive isolates within the populations in Idaho and Oregon, where the disease is endemic (3). Metalaxyl insensitivity was not detected in hop yards previously sampled in Washington (28). Phenylamide fungicides are still used to manage downy mildew in Washington, although the climate in eastern Washington tends to favor severe outbreaks in only 1 of 3 years (25). However, recent reports by growers of poor downy mildew control in some hop yards in Washington following application of phenylamide fungicides may suggest insensitivity to this class of fungicides in this region. The objectives of this research were to (i) determine the prevalence of phenylamide insensitivity among isolates of $P$. humuli from the hopproduction regions of the Pacific Northwestern United States where phenylamide insensitivity was reported previously and (ii) determine if phenylamide insensitivity is associated with recent failures in hop downy mildew disease control in Washington.

\section{MATERIALS AND METHODS}

Collection of basal spikes and maintenance of monosporic isolates. From 2005 to 2007, 201 basal spikes were collected from commercial hop yards from the major hop-growing regions in Oregon, northern Idaho, and Washington and are summarized in Table 1. Basal spikes were collected from 6,10, and 11 hop yards in Idaho, Washington, and Oregon, respectively. Twenty-five basal spikes also were collected from an experimental hop yard near Prosser, WA that has never been exposed to phenylamide fungicides (28), and these basal spikes served as negative controls in fungicide assays (described below) to ensure that assay results were not due to false positives. As such, specific comparisons between isolates from the experimental yard and commercial assays were not conducted and detailed results of isolates from the experimental yard are not presented.

Basal spikes were collected from diseased plants as arbitrarily as disease distribution allowed in each yard. No more than one basal spike was collected from adjacent plants and multiple basal spikes were not collected from a single hill to reduce the chance of collecting multiple clonal isolates of $P$. humuli. The basal spikes were placed in plastic bags with a moist

Table 1. Sensitivity to mefenoxam and metalaxyl among entire basal spike isolates of Pseudoperonospora humuli collected from hop yards in Idaho, Oregon, and Washington in 2005 and 2006

\begin{tabular}{lcclrc}
\hline Fungicide, state $^{\mathbf{a}}$ & Grower & Yard number & Cultivar & $\boldsymbol{n}^{\mathbf{c}}$ & Insensitive (\%) $^{\mathbf{b}}$ \\
\hline Mefenoxam & & & & & \\
ID & 1 & ID-1 & Saazer 72 & 2 & $2(100)$ \\
OR & 2 & OR-1 & Glacier & 4 & $3(75)$ \\
OR & 3 & OR-2 & Mt. Hood & 5 & $2(40)$ \\
OR & 3 & OR-3 & Willamette & 3 & $1(33.3)$ \\
OR & 4 & OR-4 & Nugget & 9 & $5(55.6)$ \\
OR & 4 & OR-5 & Nugget & 10 & $8(80)$ \\
OR & 5 & OR-6 & Nugget & 3 & $0(0)$ \\
OR & 5 & OR-7 & Willamette & 3 & $1(33.3)$ \\
OR & 6 & OR-8 & Crystal & 9 & $2(22.2)$ \\
OR & 6 & OR-9 & Cascade & 12 & $3(25)$ \\
OR & 7 & OR-10 & Millennium & 7 & $2(28.6)$ \\
OR & 7 & OR-11 & Glacier & 5 & $2(40)$ \\
WA & 8 & WA-1 & Chelan & 2 & $0(0)$ \\
Total & $\cdots$ & $\ldots$ & $\ldots$ & 74 & $31(41.9)$ \\
Metalaxyl & & & & & \\
ID & 1 & ID-2 & HMF & 9 & $6(66.7)$ \\
ID & 1 & ID-3 & HMF & 7 & $5(71.4)$ \\
ID & 1 & ID-4 & Saazer 72 & 5 & $4(80)$ \\
WA & 8 & WA-1 & Chelan & 15 & $0(0)$ \\
WA & 9 & WA-3 & CTZ & 5 & $2(40)$ \\
WA & 9 & WA-4 & CTZ & 22 & $22(100)$ \\
WA & 10 & WA-5 & CTZ & 2 & $0(0)$ \\
WA & 10 & WA-6 & CTZ & 3 & $1(33.3)$ \\
WA & 11 & WA-7 & CTZ & 12 & $12(100)$ \\
Total & $\ldots$ & $\ldots$ & $\ldots$ & 80 & $52(65)$ \\
\hline
\end{tabular}

${ }^{a}$ Isolates were considered insensitive to mefenoxam or metalaxyl if the incidence of sporulation on leaf disks placed on water agar amended with mefenoxam or metalaxyl at $25 \mu \mathrm{g} / \mathrm{ml}$ was at least $50 \%$ of the incidence of sporulation on leaf disks placed on nonamended media. ID = Idaho, OR $=$ Oregon, and WA = Washington.

${ }^{\mathrm{b}} \mathrm{HMF}=$ Hallertauer Mittelfrüh 102 and CTZ = cvs. Columbus, Tomahawk, and Zeus, which are very closely related cultivars and often not distinguished within the hop industry.

${ }^{\mathrm{c}}$ Number of basal spike isolates. paper towel to prevent desiccation and placed in a cooler during transport to the laboratory within $24 \mathrm{~h}$. Basal spikes collected in Washington were from yards where satisfactory control of downy mildew was not achieved with applications of mefenoxam and were suspected to contain isolates insensitive to phenylamide fungicides.

Sporulation on basal spikes was induced by misting with sterile 18 -ohm water (nanopure water; Barnstead, Dubuque, IA) before enclosing the basal spikes in plastic bags with the stems in a beaker of sterile distilled water and incubating overnight at room temperature (approximately $20^{\circ} \mathrm{C}$ ) in darkness. Sporangia were harvested by shaking each basal spike for approximately $10 \mathrm{~s}$ in $15 \mathrm{ml}$ of sterile nanopure water followed by straining through several layers of cheesecloth. A small volume of the suspension was placed in a sterile petri dish and five sporangia were removed individually in approximately $5 \mu \mathrm{l}$ of the water from the suspension with the aid of a sterile pipette under a microscope at $\times 100$ magnification. The five individual sporangia and water were inoculated onto each of five sites on the abaxial surface of a young, fully expanded leaf of the downy-mildewsusceptible cv. Nugget that was grown in a greenhouse devoid of downy mildew. The inoculated leaves were placed onto sterile dampened filter paper in petri dishes and incubated in a growth chamber at $20^{\circ} \mathrm{C}$ in a 14-h photoperiod provided by fluorescent lights (approximately $300 \mu \mathrm{mol} / \mathrm{m}^{2} / \mathrm{s}$ ). After 3 to 5 days of incubation, young lesions were apparent on the leaf and single sporangium isolations were repeated as described above from one of the resulting lesions on the leaf. Individual isolates then were maintained by weekly bulk transfers of sporangia onto new leaves. Seventynine monosporic isolates were obtained and maintained during the course of the studies. When large quantities of inocula were needed for fungicide assays, individual isolates were increased by removing a mass of sporangia from a purified isolate in $5 \mu \mathrm{l}$ of sterile nanopure water and inoculating a new leaf with the sporangia and a small volume of water in approximately 10 locations. Leaves were incubated as described above in sterile petri dishes to prevent cross-contamination of isolates.

Fungicide assays. Discriminatory dose assays. Fungicide sensitivity assays were conducted using a modification of the methods reported by Klein (28). To perform the assays, leaf disks $1 \mathrm{~cm}$ in diameter were excised from fully expanded hop leaves of the downy-mildew-susceptible cv. Symphony. Leaf disks were obtained from leaves three to five nodes from the growing tip to minimize differences in susceptibility due to ontogenic resistance $(33,38)$. Seven leaf disks were placed abaxial surface upward onto plates containing $10 \mathrm{ml}$ of water agar amended with 
metalaxyl (Ridomil 2E; Syngenta Crop Protection, Greensboro, NC) or mefenoxam as Ridomil Gold (Syngenta) $24 \mathrm{~h}$ before inoculation. Both metalaxyl and mefenoxam were utilized in these assays because earlier reports of phenylamide insensitivity in $P$. humuli utilized metalaxyl (28), but mefonoxam is the only phenylamide fungicide currently registered for use on hops. In discriminatory dose assays, the media was amended with metalaxyl or mefenoxam at $25 \mu \mathrm{g} / \mathrm{ml}$ and compared with nonamended media. The concentrations of fungicides used in discriminatory dose assays were derived from previous studies (28) for consistency and were reported to differentiate isolates that are sensitive or insensitive to these fungicides. In all assays, the fungicides were diluted in nanopure water and adjusted to $\mathrm{pH} 6.5$ for standardization before adding to sterile molten $1 \%$ agar.

Inoculum for discriminatory dose assays was obtained from both homogeneous (monosporic) and heterogeneous (entire basal spikes) sources (28). Assays with inocula from both entire basal spikes and monosporic isolates derived from the same spike were not possible in many instances because of inadequate sporulation of the entire basal spike, the time-sensitive and labor-intensive nature of these studies, or death of the monosporic isolate during maintenance on hop leaves during the course of the studies.

For assays involving entire basal spike isolates of $P$. humuli, sporulation on spikes was induced as described previously. Inoculum concentration among spike isolates ranged from approximately $10^{2}$ to $10^{6}$ sporangia/ml and was not standardized among isolates for consistency with methods reported previously (28), where sporangial concentrations had similar variability and inoculum was applied in excess. In assays utilizing inoculum obtained from monosporic isolates, inoculum was harvested from diseased leaves (described above) by rinsing a leaf inoculated 7 to 10 days prior in sterile nanopure water. Inoculum was adjusted to $10^{4}$ sporangia/ml of sterile nanopure water with the aid of a hemacytometer and used immediately. Leaf disks were inoculated by pipetting 12 $\mu \mathrm{l}$ of the sporangial suspension onto each of three spots on each of 14 leaf disks, for a total of 42 replicate inoculation sites per isolate-fungicide concentration. Due to possible differences in susceptibility to infection of individual leaves, all fungicide concentrations for a single spike or monosporic isolate utilized disks from a common set of leaves.

In all assays, the water droplet and remaining inoculum was removed $24 \mathrm{~h}$ after inoculation by aspiration. The leaf disks were incubated at $20^{\circ} \mathrm{C}$ in a 14 -h photoperiod provided by fluorescent lights. After 7 to 11 days of additional incubation, leaf disks were examined with the aid of a stereomicroscope and the incidence of inoculation sites with sporulating colonies of $P$. humuli was recorded. An isolate was considered insensitive if the incidence of sporulation on leaf disks placed on the amended media was at least $50 \%$ of the incidence of sporulation on leaf disks placed on nonamended media.

50\% Effective dose assays. For dilution assays, plates were amended with metalaxyl at $0,0.1,1,10,50,100$, and 1000 $\mu \mathrm{g} / \mathrm{ml}$ in initial assays to determine the appropriate range of metalaxyl concentrations, and later metalaxyl at $0,0.01,0.1,1$, $10,50,100$, and $500 \mu \mathrm{g} / \mathrm{ml}$ when performing assays to determine the effective dose that inhibited sporulation on $50 \%$ of the inoculation sites $\left(\mathrm{ED}_{50}\right) . \mathrm{ED}_{50}$ assays with mefenoxam were not conducted because studies conducted previously with $P$. humuli utilized metalaxyl (28), and the labor and time required for the assays were not practical or justifiable given that mefenoxam and metalaxyl have the same active ingredient. Inoculum preparation and inoculations were conducted as described previously.

Inoculum was derived from both monosporic and entire basal spike sources for $\mathrm{ED}_{50}$ assays. In all, 42 monosporic isolates were obtained and assayed from two hop yards in Idaho (5 isolates) and nine yards in Oregon (37 isolates) in 2006 and 2007. Isolates were obtained from cvs. Nugget (24 isolates), Mt. Hood (9 isolates), Hallertauer Mittelfrüh 102 (5 isolates), Centennial (3 isolates), and Crystal (1 isolate).

For assays utilizing entire basal spike isolates, 14 isolates were collected in 2006 and 33 were collected in 2007 from yards in Oregon, for a total of 47 isolates. Isolates were obtained from cvs. Nugget (30 isolates), Mt. Hood (9 isolates), Crystal (5 isolates), Centennial (2 isolates), and Willamette (1 isolate).

Statistical analysis. Scatter plots of percent inhibition relative to the $\log$ of metalaxyl concentration were constructed for each isolate assayed in a dilution series using a spreadsheet program (Microsoft Excel; Microsoft Corp., Redmond, WA), and a regression model was fit to the linear portion of the data similar to the methods reported previously $(28,43)$. $\mathrm{ED}_{50}$ values were calculated from the slope and intercept parameters of the regression models and summarized as a frequency distribution. Results where less than $50 \%$ sporulation was observed in the nonamended treatment were eliminated to minimize impacts due to the condition of the isolate (e.g., age of spike, interference due to field application of other fungicides by growers, and so on) or leaf disks, and the number of isolates reported does not include results from such instances.

The relationship between $\log \mathrm{ED}_{50}$ values obtained from entire basal spike and monosporic isolates obtained from these spikes were compared by fitting a linear regression to the $\log \mathrm{ED}_{50}$ values obtained from a subset of 30 isolates in SigmaPlot (version 9.01; Systat Software, San Jose, CA). The frequency distribution of $\log$ $\mathrm{ED}_{50}$ values among basal spike and monosporic isolates of $P$. humuli were compared with the nonparametric KolmogorovSmirnov (K-S) test using the NPAR1WAY procedure in SAS (version 9.1; SAS Institute, Cary, NC). The K-S statistic measures the maximum deviation of the empirical density function and can be used to test a null hypothesis that two data sets belong to the same distribution. Monte Carlo estimation was used to derive exact $P$ values for the K-S test. The $95 \%$ confidence intervals of the median $\log \mathrm{ED}_{50}$ of the distributions also were compared using the nonparametric sign test in Minitab (version 14; Minitab Inc., State College, PA).

Assay reproducibility. To assess the reproducibility of the assay, a subset of 21 monosporic isolates were assayed twice. The accuracy, precision, and correspondence correlation of the $\mathrm{ED}_{50}$ values obtained from each replication of the assay were quantified by the bias correction factor $\left(C_{b}\right)$, Pearson's $\rho$, and the concordance correlation coefficient $\left(\rho_{c}\right)(30)$.

\section{RESULTS}

Assay reproducibility. The concordance correlation $\left(\rho_{c}\right)$, precision $(\rho)$, and accuracy $\left(\mathrm{C}_{\mathrm{b}}\right)$ of the assay were $0.91(95 \%$ confidence interval, 0.80 to 0.96$), 0.92$, and 0.99 , respectively, where a value of 1 indicates perfect concordance (Fig. 1). Calculation of $\rho_{c}, \rho$, and $C_{b}$ was not possible with entire basal spike isolates because destructive sampling of the spike precluded replication of these assays.

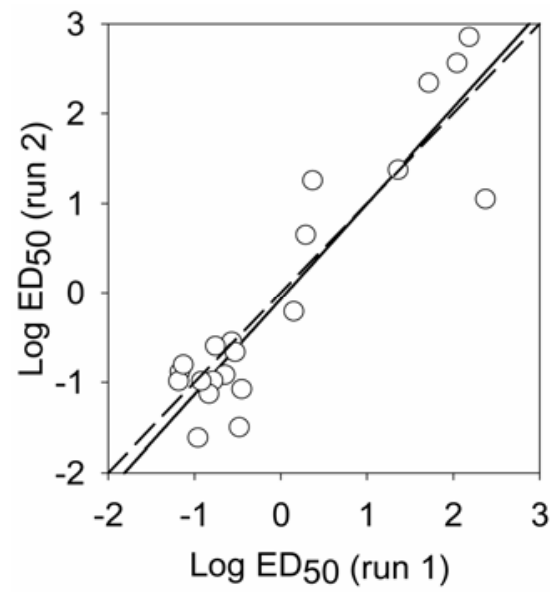

Fig. 1. Reproducibility of metalaxyl sensitivity assay for Pseudoperonospora humuli. The solid line is the linear regression model $y=1.066 x-$ $0.069\left(R^{2}=0.84\right)$ obtained from two runs of the assay with $n=21$ monosporic isolates collected from six hop yards. The dashed line represents perfect concordance. In this assay, the concordance correlation $\left(\rho_{c}\right)$ was 0.91 with $95 \%$ confidence interval 0.80 to 0.96 , precision $(\rho)$ was 0.92 , and accuracy $\left(\mathrm{C}_{\mathrm{b}}\right)$ was $0.99 . \log \mathrm{ED}_{50}=$ logarithm of the $50 \%$ effective dose. 
Discriminatory dose assays. Insensitivity to mefenoxam was detected in 31 of 74 $(41.9 \%)$ entire basal spike isolates assayed (Table 1). Mefenoxam insensitivity was detected in spikes collected from 11 of 13 $(84.6 \%)$ yards sampled and 8 of $9(88.9 \%)$ cultivars sampled. Metalaxyl insensitivity was detected in 52 of $80(65 \%)$ spikes, 7 of

Table 2. Metalaxyl insensitivity among monosporic isolates of Pseudoperonospora humuli collected from hop yards in Idaho and Washington in 2006

\begin{tabular}{lcclcc}
\hline State $^{\mathbf{a}}$ & Grower & Yard number & Cultivar $^{\mathbf{b}}$ & $\boldsymbol{n}^{\mathbf{c}}$ & ${\text { Insensitive }(\boldsymbol{\%})^{\mathbf{d}}}^{\text {(n) }}$ \\
\hline ID & 1 & ID-2 & HMF & 4 & $3(75)$ \\
ID & 1 & ID-3 & HMF & 4 & $2(50)$ \\
ID & 1 & ID-5 & HMF & 1 & $0(0)$ \\
ID & 1 & ID-6 & HMF & 2 & $0(0)$ \\
WA & 9 & WA-3 & CTZ & 1 & $0(0)$ \\
WA & 10 & WA-5 & CTZ & 4 & $1(25)$ \\
WA & 10 & WA-6 & CTZ & 2 & $2(100)$ \\
WA & 8 & WA-1 & CTZ & 14 & $0(0)$ \\
WA & 12 & WA-8 & Cluster & 1 & $0(0)$ \\
WA & 13 & WA-9 & Cluster & 1 & $0(0)$ \\
WA & 14 & WA-10 & Cluster & 3 & $0(0)$ \\
Total & $\ldots$ & $\ldots$ & $\ldots$ & 37 & $8(21.6)$ \\
\hline
\end{tabular}

a ID = Idaho and WA= Washington.

${ }^{\mathrm{b}} \mathrm{HMF}=$ Hallertauer Mittelfrüh 102 and CTZ = cvs. Columbus, Tomahawk, and Zeus, which are very closely related cultivars and often not distinguished within the hop industry.

c Number of isolates.

${ }^{\mathrm{d}}$ Isolates were considered insensitive to metalaxyl if the incidence of sporulation on inoculated leaf disks placed on water agar amended with metalaxyl at $25 \mu \mathrm{g} / \mathrm{ml}$ was at least $50 \%$ of the incidence of sporulation on leaf disks on nonamended media.
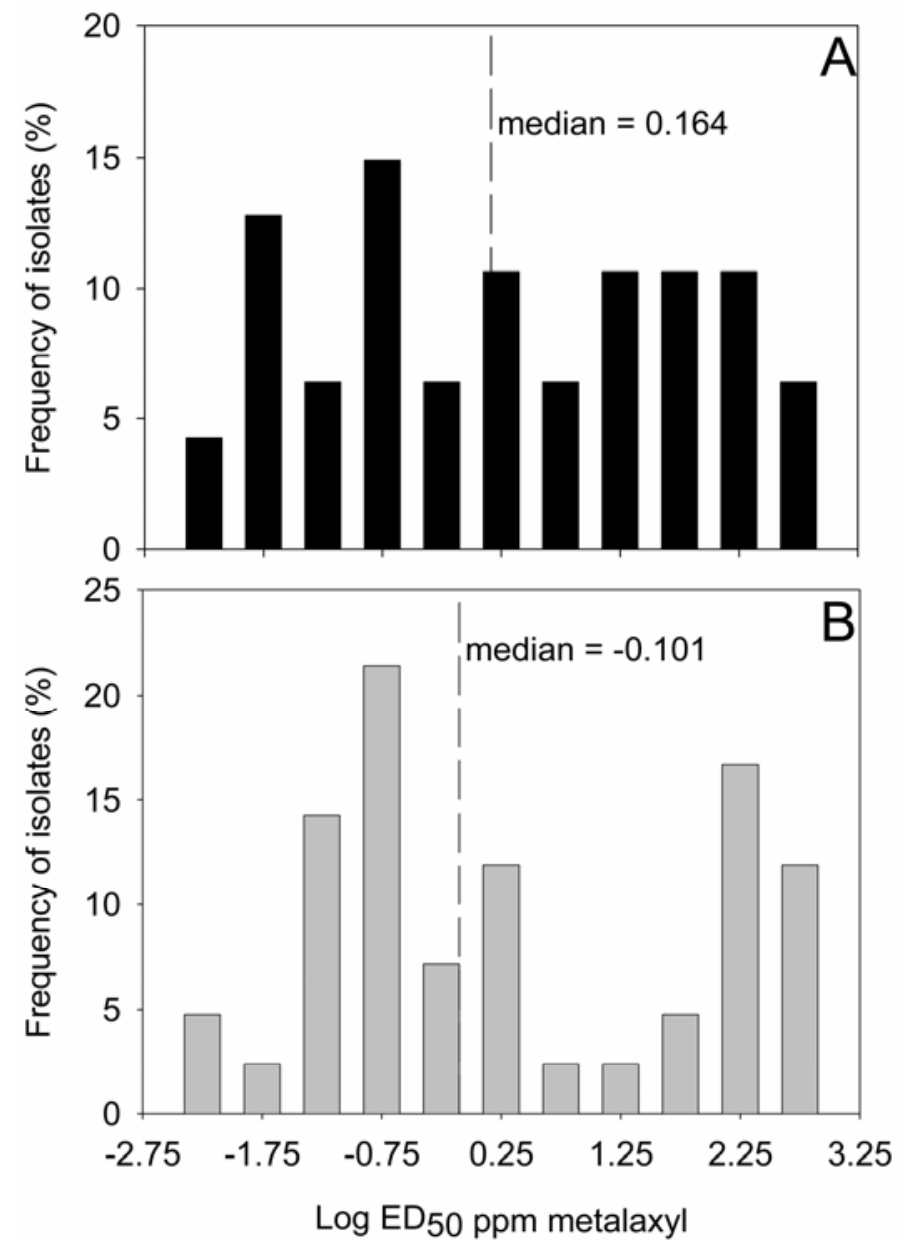

Fig. 2. Frequency distribution of the logarithm of the $50 \%$ effective dose $\left(E_{50}\right)$ of metalaxyl among A, 47 basal spike isolates and B, 42 monosporic isolates of Pseudoperonospora humuli. Isolates were collected from A, nine hop yards in Oregon in 2005 to 2007 and B, eight yards in Oregon (37 isolates) and Idaho ( 5 isolates) collected in 2006 and 2007. The Kolmogorov-Smirnov test statistic $D=0.137$ with $99 \%$ confidence interval for the $P$ value $=0.714$ to 0.737 , indicating that the data belong to the same distribution. The $95 \%$ confidence interval of the medians overlapped as determined by a sign test, indicating that the medians for the distributions do not differ significantly.

$9(77.8 \%)$ yards, and 3 of $4(75 \%)$ cultivars tested. Metalaxyl insensitivity was detected in four of five hop yards sampled in Washington.

Among monosporic isolates of $P$. humuli, insensitivity to metalaxyl was detected in 8 of $37(21.6 \%)$ isolates representing 4 of 11 (36.4\%) yards and 2 of 3 (66.7\%) cultivars assayed (Table 2). Metalaxyl insensitivity also was detected in monosporic isolates obtained from spikes collected in Washington. It is important to note that the hop yards, cultivars, and sampling times differed among the assays with mefenoxam and metalaxyl and spike or monosporic isolates. Therefore, insensitivity among these compounds and inoculum sources was not expected to be identical.

ED $_{50}$ assays. $\log \mathrm{ED}_{50}$ values ranged from -2.25 to 2.67 for entire basal spike isolates and -2.27 to 2.98 for monosporic isolates (Fig. 2). Among the isolates assayed in the dilution series of metalaxyl, 14 of $47(29.8 \%)$ spike isolates and 14 of $42(33.3 \%)$ monosporic isolates had $\mathrm{ED}_{50}$ values greater than $25 \mu \mathrm{g} / \mathrm{ml}$.

The distribution of $\log \mathrm{ED}_{50}$ values were bimodal for inoculum derived from both entire basal spikes and monosporic isolates, and did not fit the log-normal distribution ( $P=0.016$ and 0.005 , respectively). The frequency distribution of $\log \mathrm{ED}_{50}$ values was right-skewed for assays with inoculum from both entire basal spikes and monosporic isolates, with median $\log \mathrm{ED}_{50}$ $=0.164$ and -0.101 , respectively. The $95 \%$ confidence intervals of the medians were not significantly different. The null hypothesis of the K-S test also could not be rejected $(99 \%$ confidence interval of $P=$ 0.714 to 0.737 ), indicating that the data sets were derived from the same distribution and that the population of $\log \mathrm{ED}_{50}$ values for spike and monosporic isolates were similar.

Among 30 basal spike isolates where monosporic isolations were obtained from each of the spikes, the $\log \mathrm{ED}_{50}$ values for the monosporic isolates and corresponding entire basal spike were significantly associated $\left(R^{2}=0.47 ; P<0.0001 ;\right.$ Fig. 3$)$. The slope of the regression line was $<1 \quad(P<$ $0.0001)$, indicating that the $\log \mathrm{ED}_{50}$ values obtained from entire basal spike isolates were greater than the corresponding $\log \mathrm{ED}_{50}$ values obtained from a monosporic isolate obtained from that spike.

\section{DISCUSSION}

The nearly complete control of hop downy mildew reported by Hunger and Horner (21) in 1982 was followed quickly by documentation of insensitivity to this compound in Germany (19) and the United States (28). This research demonstrates that insensitivity to phenylamide fungicides remains prevalent among isolates of $P$. humuli in the Pacific Northwest despite limited or nonuse of these fungicides for 
control of downy mildew for approximately two decades. This is also the first report of phenylamide insensitivity in $P$. humuli in Washington. Because conditions favorable for severe hop downy mildew epidemics tend to occur once every 3 years in Washington (25), the prevalence of insensitive strains of $P$. humuli in certain Washington hop yards may have important implications for management of this disease (e.g., increased application frequency with other fungicides) (32).

Insensitivity to mefenoxam or metalaxyl was detected in 46 of $93(49.5 \%)$ basal spikes collected from Oregon and Idaho. Compared with the results of Klein (28), where 87 of $104(83.7 \%)$ spikes assayed from these states were insensitive to metalaxyl, it appears that the prevalence of phenylamide insensitivity has decreased to some degree since 1994. However, the sample size from Idaho was relatively small and additional sampling is needed to more precisely quantify the level of phenylamide insensitivity in the population. Nonetheless, phenylamide insensitivity was detected in greater than $10 \%$ of isolates from Idaho. In instances where metalaxyl insensitivity is present at a low (approximately 10\%) frequency among isolates in a population, selection for high levels of insensitivity may occur within a single season (18). Gisi (16) suggested that disease control failures may occur with phenylamide fungicides under field conditions when insensitivity is detected in 10 to $15 \%$ of isolates within a population, although the level of disease suppression clearly also depends on other factors, such as the rate of epidemic development and host phenology. In the present study, sampling within individual hop yards was insufficient to determine the incidence of insensitivity within a particular yard. However, given that phenylamide insensitivity was detected in nearly half of the spikes sampled from Oregon and Idaho, it is not likely that these fungicides would provide satisfactory suppression of hop downy mildew under field conditions.

The distribution of metalaxyl sensitivity was similar among inoculum sources obtained from spikes and monosporic isolates. Regression analysis indicated that approximately $47 \%$ of the variation in $\log$ $\mathrm{ED}_{50}$ values of monosporic isolates could be explained by assaying the entire basal spike from which a monosporic isolate was obtained. Unfortunately, the distribution of $\mathrm{ED}_{50}$ values was not available for $P$. $h u$ muli before the use of phenylamide fungicides in the Pacific Northwest, and data from only nine spikes is available from previous studies (28), precluding such comparison.

Ypema et al. (44) reported that, with the grape powdery mildew fungus Uncinula necator, mean population $\mathrm{ED}_{50}$ values tended to be higher when inoculum was obtained from heterogeneous sources compared with monoconidial isolates. The authors suggested that heterogeneous inoculum sources may be used to determine the highest level of insensitivity in a population but that monoconidial isolates are required for population biology research and sensitivity correlation studies. We concur with these statements for the $P$. humuli-hop pathosystem. In the present study, $\mathrm{ED}_{50}$ values tended to be consistent between inoculum derived from spikes (according to methods described previously; 28) and monosporic isolates; however, there was considerable variation among individual isolates. We also found that inoculum derived from a heterogeneous source generally had a greater $\mathrm{ED}_{50}$ than monosporic isolates, as determined by a slope of the regression line less than 1 . Assays involving whole spikes likely are as suitable as, or perhaps superior to, monosporic isolates for routine insensitivity monitoring because the highest level of fungicide tolerance may be of interest practically. The relationship between assay results for spike and monosporic isolates determined in this study should aid other researchers working with $P$. humuli to determine the most appropriate inoculum source to assay given the objectives of their research.

In other oomycete pathosystems, the incidence of phenylamide insensitivity has been reported to diminish in populations in the absence of selection pressure for insensitivity (11-14). In the case of Phytophthora infestans on potato, Dowley et al. (12) reported that metalaxyl was used, strategically, on greater than $80 \%$ of potato crops in Ireland in 1998 and provided useful levels of disease suppression, although widespread metalaxyl insensitivity was detected 17 years earlier in that country. Previous studies with $P$. infestans indicate that metalaxyl-sensitive and -insensitive isolates differ in their competitive fitness $(6,11,20,27)$. Mechanisms associated with the stability of phenylamide insensitivity in Pseudoperonospora humuli were beyond the scope of the present research; however, fitness and virulence of phenylamideinsensitive isolates should be addressed in future research to determine its importance in persistence of phenylamide sensitivity in this pathosystem.

Persistence of phenylamide insensitivity in P. humuli and perhaps systemic oomycete pathogens of other perennial hosts (1) also may be related to the perennation of the pathogen within systemically infected crown tissues $(8,40)$. Johnson and Anliker (23) reported that hop downy mildew epidemics can be polyetic because of infection of the perennial hop crowns. Because of the ability of $P$. humuli to survive within infected hop plants and provide the initial inoculum for disease outbreaks in following seasons $(22,23)$, insensitive strains of $P$. humuli potentially may persist in hop yards relatively longer than in oomycete pathogens in annual systems (e.g., Phytophthora infestans on potato).

An alternative explanation for the relatively high levels of phenylamide insensitivity in Oregon and Idaho is that growers have used these fungicides periodically in hopes of achieving some suppression of downy mildew, thus maintaining selection pressure on the population. Grower interviews indicated that this did not occur or did not occur frequently enough for growers to recall using phenylamides in the past 10 to 15 years. Insensitivity to phenylamide fungicides involves multiple genetic loci (26) and it is unclear how these loci contribute to the phenotype stability and fitness in Pseudoperonospora humuli.

Detection of phenylamide insensitivity in P. humuli in Washington is significant and indicates that growers in this region need to implement resistance management programs, as have been developed in other systems $(12,16,20)$, and adopt alternative control strategies for downy mildew in some yards $(38,41)$. Resistance management strategies would include limiting the frequency of applications of phenylamide fungicides (12), avoiding soil applications (38), using fungicides with diverse modes of action in rotation or tank mixes (16), and increasing use of other disease management strategies that reduce inoculum levels. The latter may include rouging of systematically infected crowns $(7,40)$, removal of basal spikes (36), strategic selection of moderately resistant cultivars in yards with a history of downy mildew $(38,41)$, and modification of spring pruning practices to delay epidemic development (41). Strict adherence to resistance management strategies is particularly important given the findings of the current study that phenylamide insensitivity has persisted in isolates of $P$. humuli in hopproduction regions in Idaho and Oregon.

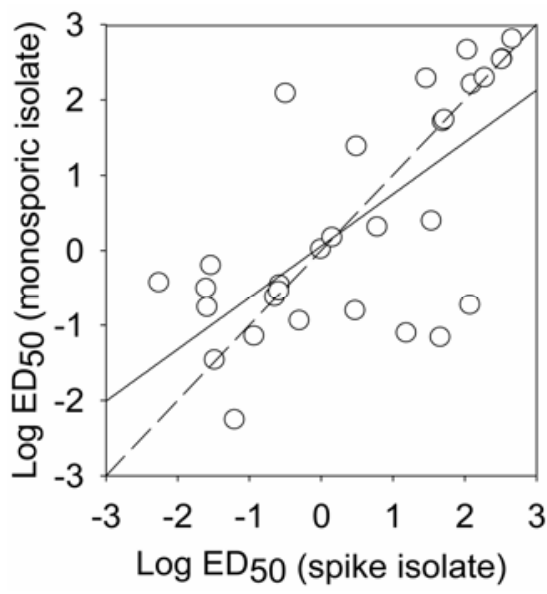

Fig. 3. Association between logarithm of the $50 \%$ effective dose $\left(\mathrm{ED}_{50}\right)$ of metalaxyl among 30 basal spike and monosporic isolates of Pseudoperonospora humuli. The solid line is the linear regression model $y=0.69 x+0.059\left(R^{2}=\right.$ $0.47 ; P<0.0001)$. The dashed line represents perfect concordance. 
In conclusion, this research suggests that insensitivity to phenylamide fungicides is a stable phenotype in $P$. humuli. Management of downy mildew should rely on measures other than these fungicides alone in yards or regions where insensitivity is prevalent, which is now known to include certain hop yards in Idaho, Oregon, and Washington. The distribution of sensitivity to metalaxyl among spike and monosporic isolates of $P$. humuli also will provide a baseline for future studies to quantify further changes in sensitivity.

\section{ACKNOWLEDGMENTS}

Financial support was provided by United States Department of Agriculture-Agricultural Research Service CRIS 5358-21000-035-00 and Washington State University, and grants from the Hop Research Council and the Washington Hop Commission. We thank N. Adair, E. Krahn, N. Tierney, and J. Woods for excellent technical support; and the many hop growers that allowed us access to their yards for sampling.

\section{LITERATURE CITED}

1. Aegerter, B. J., Nunez, J. J., and Davis, R. M. 2002. Detection and management of downy mildew in rose rootstock. Plant Dis. 86:13631368.

2. Albourie, J. M., Tourvieille, J., and Tourvieille-De Labrouhe, D. 1998. Resistance to metalaxyl in isolates of the sunflower pathogen Plasmopara halstedii. Eur. J. Plant Pathol. 104:235-242.

3. Barth, H. J., Klinke, C., and Schmidt, C. 1994. The Hop Atlas. Joh. Barth and Sohn, Nuremberg, Germany.

4. Bruck, R. I., Gooding, G. V., Jr., and Main, C. E. 1982. Evidence for resistance to metalaxyl by isolates of Peronospora hyoscyami. Plant Dis. 66:44-45.

5. Cohen, Y., and Reuveni, M. 1983. Occurrence of metalaxyl-resistant isolates of Phytophthora infestans in potato fields in Israel. Phytopathology 73:925-927.

6. Cohen, Y., Reuveni, M, and Samoucha, Y. 1983. Competition between metalaxylresistant and -sensitive strains of Pseudoperonospora cubensis on cucumber plants. Phytopathology 73:1516-1520.

7. Coley-Smith, J. R. 1964. Persistence and identification of downy mildew Pseudoperonospora humuli (Miy + Tak) Wilson in hop rootstocks. Ann. Appl. Biol. 53:129-132.

8. Coley-Smith, J. R. 1965. Infection of hop rootstocks by downy mildew Pseudoperonospora humuli (Miy. et Tak.) Wilson and its control by early-season dusts. Ann. Appl. Biol. 56:381-388.

9. Davidse, L. C., Looijei, D., Turkensteen, L. J., and Van Der Wal, D. 1981. Occurrence of metalaxyl-resistant strains of potato blight in Dutch potato fields. Neth. J. Plant Pathol. 87:65-68.

10. Derie, M. L., and Inglis, D. A. 2001. Persistence of complex virulences in populations of Phytophthora infestans in western Washington. Phytopathology 91:606-612.

11. Dowley, L. J. 1987. Factors affecting the survival of metalaxyl-resistant strains of Phy- tophthora infestans (Mont.) de Bary in Ireland. Potato Res. 30:473-475.

12. Dowley, L. J., Griffin, D., and O'Sullivan, E. 2002. Two decades of monitoring Irish populations of Phytophthora infestans for phenylamide resistance. Potato Res. 45:79-84.

13. Dowley, L. J., and O'Sullivan, E. 1981. Metalaxyl-tolerant strains of Phytophthora infestans (Mont.) de Bary in Ireland. Potato Res. 24:417-421.

14. Dowley, L. J., and O'Sullivan, E. 1985. Monitoring metalaxyl resistance in populations of Phytophthora infestans. Potato Res. 28:531534.

15. Ferrin, D. M., and Kabashima, J. N. 1991. In vitro insensitivity to metalaxyl of isolates of Phytophthora citricola and $P$. parasitica from ornamental hosts in southern California. Plant Dis. 75:1041-1044.

16. Gisi, U. 1998. Population dynamics in peronosporales treated with phenylamide fungicides. Pages 66-71 in: Fungicide Resistance in North America. C. J. Delp, ed. American Phytopathological Society Press, St. Paul, MN

17. Goodwin, S. B., Sujowski, L. S., and Fry, W. E. 1996. Widespread distribution and probable origin of resistance to metalaxyl in clonal genotypes of Phytophthora infestans in the United States and Canada. Phytopathology 86:793-800.

18. Grünwald, N. J., Sturbaum, A. K., Romero Montes, G., Garay Serrano, E., LozoyaSaldaña, H., and Fry, W. E. 2006. Selection for fungicide resistance within a growing season in field populations of Phytophthora infestans at the center of origin. Phytopathology 96:1397-1403.

19. Hellwig, K., Kremheller, H. T., and Agerer, R. 1991. Untersuchen zur resistenz von Pseudoperonospora humuli (Miy. \& Tak.)Wilson gegenuber metalaxyl. Gesunde Pflanz. 43:400404.

20. Holmes, S. J. I., and Channon, A. G. 1984. Studies on metalaxyl-resistant Phytophthora infestans in potato crops in south-west Scotland. Plant Pathol. 33:347-354.

21. Hunger, R. M., and Horner, C. E. 1982. Control of hop downy mildew with systemic fungicides. Plant Dis. 66:1157-1159.

22. Johnson, D. A. 1991. Two degree-day models for predicting initial emergence of hop shoots systemically infected with Pseudoperonospora humuli. Plant Dis. 75:285-87.

23. Johnson, D. A., and Anliker, W. L. 1985. Effect of downy mildew epidemics on the seasonal carryover of initial inoculum in hop yards. Plant Dis. 69:140-142.

24. Johnson, D. A., and Skotland, C. B. 1985. Effects of temperature and relative humidity on sporangium production of Pseudoperonospora humuli on hop. Phytopathology 75:127129.

25. Johnson, D. A., Skotland, C. B., and Alldredge, J. R. 1983. Weather factors affecting downy mildew epidemics of hops in the Yakima Valley of Washington. Phytopathology 73:489-493.

26. Judelson, H. S., and Roberts, S. 1999. Multiple loci determining insensitivity to phenylamide fungicides in Phytophthora infestans. Phytopathology 89:754-760.

27. Kadish, D., and Cohen, Y. 1998. Competition between metalaxyl-sensitive and metalaxylresistant isolates of Phytophthora infestans in the absence of metalaxyl. Plant Pathol. 37:558-564.

28. Klein, R. E. 1994. Occurrence and incidence of metalaxyl resistance in Pseudoperonospora humuli in the Pacific Northwest. Plant Dis. 78:161-163.

29. Lamour, K. H., and Hausbeck, M. K. 2000. Mefenoxam insensitivity and the sexual stage of Phytophthora capsici in Michigan cucurbit fields. Phytopathology 90:396-400.

30. Madden, L. V., Hughes, G., and van den Bosch, F. 2007. The Study of Plant Disease Epidemics. American Phytopathological Society Press, St. Paul, MN

31. Miller, J. S., Hamm, P. B., and Johnson, D. A. 1997. Characterization of the Phytophthora infestans population in the Columbia Basin of Oregon and Washington from 1992 to 1995 Phytopathology 87:656-660.

32. Nelson, M. E., Eastwell, K. C., Grove, G. G., Barbour, J. D., Ocamb, C. M., and Alldredge, J. R. 2004. Sensitivity of Pseudoperonospora humuli (the casual agent of hop downy mildew) from Washington, Idaho, and Oregon to fosetyl-Al (Aliette). Online. Plant Health Progress doi:10.1094/PHP-2004-0811-01-RS.

33. Neve, R. A. 1991. Hops. Chapman and Hall, London.

34. Parra, G., and Ristaino, J. B. 2001. Resistance to mefenoxam and metalaxyl among field isolates of Phytophthora capsici causing Phytophthora blight of bell pepper. Plant Dis. 85:1069-1075.

35. Reuveni, M., Eyal, H., and Cohen, Y. 1980 Development of resistance to metalaxyl in Pseudoperonospora cubensis. Plant Dis. 64:1108-1109.

36. Romanko, R. R. 1964. Control of hop downy mildew by chemical desiccants. Phytopathology 54:1439-1442.

37. Royle, D. J. 1973. Quantitative relationships between infection by the hop downy mildew pathogen, Pseudoperonospora humuli, and weather and inoculum factors. Ann. Appl. Biol. 73:19-30.

38. Royle, D. J., and Kremheller, H. TH. 1981. Downy mildew of the hop. Pages 395-419 in: The Downy Mildews. D. M. Spencer, ed. Academic Press, New York.

39. Schettini, T. M., Legg, E. J., and Michelmore, R. W. 1991. Insensitivity to metalaxyl in California populations of Bremia lactucae and resistance of California lettuce cultivars to downy mildew. Phytopathology 81:64-70.

40. Skotland, C. B. 1961. Infection of hop crowns and roots by Pseudoperonospora humuli and its relation to crown and root rot and overwintering of the pathogen. Phytopathology 51:241-244.

41. Skotland, C. B., and Johnson, D. A. 1983. Control of downy mildew of hops. Plant Dis. 67:1183-1185.

42. Taylor, R. J., Salas, B., Secor, G. A., Rivera, V., and Gudmestad, N. C. 2002. Sensitivity of North American isolates of Phytophthora erythroseptica and Pythium ultimum to mefenoxam (metalaxyl). Plant Dis. 86:797-802.

43. Wong, F. P., and Wilcox, W. F. 2000. Distribution of baseline sensitivities to azoxystrobin among isolates of Plasmopara viticola. Plant Dis. 84:275-281.

44. Ypema, H. L., Ypema, M., and Gubler, W. D. 1997. Sensitivity of Uncinula necator to benomyl, triadimefon, myclobutanil, and fenarimol in California. Plant Dis. 81:293-297. 